\title{
ВMJ Global Health Tracking the uptake and trajectory of COVID-19 vaccination coverage in 15 West African countries: an interim analysis
}

Muhammed Olanrewaju Afolabi (D) , ${ }^{1}$ Oghenebrume Wariri (D) , ${ }^{2,3}$ Yauba Saidu, ${ }^{4,5}$ Akaninyene Otu (D) , 6,7 Semeeh Akinwale Omoleke (D) , 8 Bassey Ebenso (D) ,9 Adekola Adebiyi, ${ }^{10}$ Michael Ooko, ${ }^{11}$ Bright Opoku Ahinkorah (D) ,12 Edward Kwabena Ameyaw (D) , ${ }^{12}$ Abdul-Aziz Seidu (D) , ${ }^{13,14}$ Emmanuel Agogo, ${ }^{15}$ Terna Nomhwange, ${ }^{16}$ Kolawole Salami, ${ }^{17}$ Nuredin Ibrahim Mohammed (D) , 2,11 Sanni Yaya (D) 18,19

To cite: Afolabi M0, Wariri 0, Saidu Y, et al. Tracking the uptake and trajectory of COVID-19 vaccination coverage in 15 West African countries: an interim analysis. BMJ Global Health 2021;6:e007518. doi:10.1136/ bmjgh-2021-007518

Handling editor Seye Abimbola

- Additional supplemental material is published online only. To view, please visit the journal online (http://dx.doi.org/10. 1136/bmjgh-2021-007518).

MOA and $\mathrm{OW}$ are joint first authors.

NIM and SY are joint senior authors.

Received 23 September 2021 Accepted 28 0ctober 2021

\section{Check for updates}

C Author(s) (or their employer(s)) 2021. Re-use permitted under CC BY-NC. No commercial re-use. See rights and permissions. Published by BMJ.

For numbered affiliations see end of article.

\section{Correspondence to}

Dr Muhammed Olanrewaju Afolabi;

Muhammed.Afolabi@Ishtm. ac.uk

\section{ABSTRACT}

The African Union Bureau of Heads of State and Government endorsed the COVID-19 Vaccine Development and Access Strategy to vaccinate at least $60 \%$ of each country's population with a safe and efficacious vaccine by 2022 , to achieve the population-level immunity needed to bring the pandemic under control. Using publicly available, country-level population estimates and COVID-19 vaccination data, we provide unique insights into the uptake trends of COVID-19 vaccinations in the 15 countries that comprise the Economic Community of West Africa States (ECOWAS). Based on the vaccination rates in the ECOWAS region after three months of commencing COVID-19 vaccinations, we provide a projection of the trajectory and speed of vaccination needed to achieve a COVID-19 vaccination coverage rate of at least $60 \%$ of the total ECOWAS population. After three months of the deployment of COVID-19 vaccines across the ECOWAS countries, only $0.27 \%$ of the region's total population had been fully vaccinated. If ECOWAS countries follow this trajectory, the sub-region will have less than $1.6 \%$ of the total population fully vaccinated after 18 months of vaccine deployment. Our projection shows that to achieve a COVID-19 vaccination coverage of at least $60 \%$ of the total population in the ECOWAS sub-region after 9 , 12 and 18 months of vaccine deployment; the speed of vaccination must be increased to 10,7 and 4 times the current trajectory, respectively. West African governments must deploy contextually relevant and culturally acceptable strategies for COVID-19 vaccine procurements, distributions and implementations in order to achieve reasonable coverage and save lives, sooner rather than later.

\section{INTRODUCTION}

The unparalleled speed of development of COVID-19 vaccines demonstrates humanity's resilience, ingenuity and cooperation in
Summary box

The unparalleled speed at which the COVID-19 vaccines were developed brought a renewed hope that the acute phase of the pandemic was almost over, but the inequitable global distribution of the vaccines has contributed to the emergence of mutant strains.

- The African Union Bureau of Heads of State and Government endorsed the COVID-19 Vaccine Development and Access Strategy with the goal of vaccinating at least $60 \%$ of each country's population with safe and efficacious vaccines by 2022 to achieve the population-level immunity needed to bring the pandemic under control.

- Literature documenting vaccine uptake and the trajectory needed to achieve full vaccination at a subregional or country- level is scanty.

- Using publicly available data, we provide contextspecific information on full COVID-19 vaccination rates after 3 months of vaccine deployment in West Africa and describe the trajectory needed to achieve a full COVID-19 vaccination coverage rate of at least $60 \%$ of the total population in West Africa.

- This information will help to guide future plans for the implementation of COVID-19 vaccinations in the sub-region.

overcoming challenges. The acceptance and high uptake of COVID-19 vaccines are vital to attaining sufficient immunisation coverage to control the pandemic. A recent study across 10 low-income and middle-income countries (LMICs) reported significantly higher COVID-19 vaccine acceptance on average $(80.3 \%)$, compared with the USA $(64.6 \%)$ and Russia $(30.4 \%) .{ }^{1}$ These findings suggest that prioritising vaccine distribution to the global South would help to ensure greater 
population coverage and accelerate global efforts to end the acute phase of the COVID-19 pandemic.

The inadequate global coverage of COVID-19 vaccines, with approximately $60 \%$ of people in high-income countries (HICs) receiving at least one dose of a COVID-19 vaccine by 15 September 2021, compared with a paltry $3 \%$ of people in Africa ${ }^{2}$ could potentially trigger the emergence of mutant strains that could render the vaccines less effective. Many stakeholders have vehemently criticised this glaring inequality as causing a dangerous divergence in COVID-19 survival rates, ${ }^{3}$ with the world described as being 'on the brink of a catastrophic moral failure'. ${ }^{4}$ Despite the recent sharing of excess COVID-19 vaccines by wealthy countries, the inequity gap remains very wide as nearly $90 \%$ of African countries were unable to vaccinate $10 \%$ of their populations by the end of September 2021. ${ }^{5}$

Besides these disturbing developments, variations exist in the COVID-19 epidemiology and vaccination implementation within the African sub-regions. For example, West Africa accounts for $10 \%$ of the confirmed cases and $5 \%$ of the total deaths recorded in Africa, compared with other African sub-regions such as South, North and East Africa with higher proportions of confirmed cases and deaths. ${ }^{6}$ The relatively low numbers of confirmed COVID-19 cases and deaths in West Africa appear to have created an optimistically biased perception of selfprotection from SARS-CoV-2 infection by a substantial population of West African inhabitants. This perception manifests itself in widespread vaccine hesitancy and low uptake of the COVID-19 vaccines in many West African countries. $^{7-10}$

Most publications on COVID-19 vaccinations in Africa have focused on preparedness, hesitancy, and manufacturing capacity, ${ }^{9-11}$ while literature documenting vaccine uptake at a sub-regional or country-level is scanty. Given the heterogeneity in COVID-19 vaccination implementation across African countries, a need exists to set up a monitoring framework to track the progress of COVID-19 vaccination programmes at sub-regional levels in order to provide robust, context-specific information that could guide future implementations of COVID-19 vaccinations in the sub-region. This article aims to provide unique insights into the trends in uptake of COVID-19 vaccines in the 15 countries that comprise the Economic Community of West Africa States (ECOWAS), using publicly available and country-specific COVID-19 vaccination data. The secondary objective of this study is to forecast the trajectory of COVID-19 vaccinations in the 15 ECOWAS countries to determine their vaccination performance against the target of vaccinating at least $60 \%$ of the population by $2022 .{ }^{12}$

\section{BACKGROUND TO DATA CURATION}

We conducted a retrospective, multi-country analysis of national COVID-19 vaccination coverage and uptake among the overall population in the 15 ECOWAS countries, from the time of inception of vaccine roll-out until three months after deployment of COVID-19 vaccinations in each country. The ECOWAS is an alliance whose aim is to promote regional integration and visafree trans-border migration for all West Africans. ${ }^{13}$ The 15-member regional bloc comprises Benin, Burkina Faso, Cape Verde, Côte d'Ivoire, The Gambia, Ghana, Guinea, Guinea Bissau, Liberia, Mali, Niger, Nigeria, Senegal, Sierra Leone and Togo.

According to the latest UN estimates, the population of the countries of the member states of ECOWAS was 410 million, on 1 September 2021, accounting for about $5 \%$ of the world population. ${ }^{14}$ All 15 countries of ECOWAS are part of the 92 LMICs eligible to participate in the COVAX Facility supported by the COVAX Advance Market Commitment, an innovative funding mechanism established to enable Gavi to subsidise vaccine purchase through the COVAX Facility for resource-constrained countries. ${ }^{15}$ In addition, by belonging to the African Union, the 15 countries of ECOWAS also benefit from COVID-19 vaccine allocations by the Africa Vaccine Acquisition Task Team (AVATT). ${ }^{16}$ Individual countries in West Africa also received COVID-19 vaccines as donations from bilateral partners. ${ }^{6}$

\section{DATA SOURCES AND ANALYSIS}

We extracted COVID-19 vaccination data obtained from the country vaccination implementation teams in West Africa through the WHO Africa COVID-19 Vaccination Dashboard $^{6}$ and Our World in Data's COVID-19 Data Explorer. ${ }^{17}$ We also obtained data on the dates when each country received the first shipment of the vaccines, dates each country started vaccinations, the vaccine types, and their sources from the WHO Africa COVID-19 Vaccination Dashboard. ${ }^{6}$ From the UN World Population Prospects 2020, we extracted data on the population in each of the 15 West African countries. ${ }^{14}$ Given the ad-hoc implementations of COVID-19 vaccinations across many ECOWAS countries in which the vaccinations were prioritised for political leaders and top government officials alongside front-line healthcare workers; and in other instances, where COVID-19 vaccinations were opened up to all persons above 18 years who were willing to receive the vaccines ${ }^{18}$; it was impracticable to obtain reliable and accurate proportions of the populations targeted for the first phase of the vaccinations, hence we did not include these data in our analysis.

All statistical analyses were conducted using the $\mathrm{R}$ Statistical Software. ${ }^{19}$ Descriptive and regression analyses were performed, and the results were presented by vaccination performance at ECOWAS and country levels.

\section{ESTIMATING COVID-19 VACCINATION COVERAGE TRENDS}

We estimated COVID-19 vaccination uptake and coverage by tracking the number of people who received a first dose of the vaccine (COV-1) and those who received a second dose, that is, those who were fully vaccinated 
(COV-2), and calculated the proportion of people who received at least one dose of a COVID-19 vaccine based on each country's total population. We computed the proportion of people vaccinated in the West African subregion by dividing the total vaccinated by the total population across the 15 countries included.

\section{DETERMINING VACCINATION TRAJECTORY FROM VACCINATION RATES}

On 20 August 2020, the African Union Bureau of Heads of State and Government endorsed the COVID-19 Vaccine Development and Access Strategy with the goal of vaccinating at least $60 \%$ of each country's population with safe and efficacious vaccines by 2022, to achieve the population-level immunity needed to bring the pandemic under control. ${ }^{12}$ To achieve this target, we projected the kinetics of vaccinating at least $60 \%$ of the entire ECOWAS population and for each country of ECOWAS. We conducted a simple linear interpolation to compute the COVID-19 vaccination rates in the 15 ECOWAS countries. The first day in the analysis was the day when vaccinations started in a particular country, making the calculations not dependent on the calendar time, thereby facilitating across country computations. Although many factors may affect the vaccination rates in a country, the analysis considered a simple linear relationship between the days and vaccination coverage. In other words, the task of calculating the rate at which vaccine coverage should increase over the coming months in order to reach a targeted vaccine coverage can still be achieved with the simple linear model, assuming the factors or conditions needed are met. We calculated the initial slope as the rate of change in the vaccination coverage from the first day of the vaccine roll-out until three months, after vaccine roll-out in each ECOWAS country. We estimated the vaccination rates based on the average vaccination rate in each of the 15 ECOWAS countries (ie, slope estimate based on the average value over the 15 ECOWAS countries). We also computed the pace of vaccine coverage required to achieve vaccine targets in each of the countries, as well as the entire 15 ECOWAS countries using simple linear regression (see online supplemental appendix for model details and examples). Subsequently, we calculated the projections for vaccination trends to achieve 50\%, $60 \%$ and $70 \%$ vaccination coverages at 9,12 and 18 months since first vaccine roll-out.

\section{FINDINGS OF THE ANALYSIS OF THE DATASETS}

Senegal was the first country in West Africa to receive COVID-19 vaccines through the COVAX facility on 17 February 2021. This was followed by Sierra Leone, Ghana and Côte d'Ivoire, which received their first supplies on the 18 February 2021, 24 February 2021 and 26 February 2021, respectively (figure 1A). Burkina Faso was the last West African country to receive vaccine supplies through the COVAX Facility on 30 May 2021. The number of initial doses received ranged from 24000 doses in Cape Verde with a total population of 556000 people to 3.9 million doses in Nigeria with 211 million people (figure $1 \mathrm{~B}$ and table 1 ).

The first set of West African countries to deploy their COVID-19 vaccines included Senegal, Ghana, Côte d'Ivoire and Nigeria on 22 February 2021, 1 March 2021, 1 March 2021 and 4 March 2021, respectively (figure 1A). The time from the arrival of vaccines to deployment was as short as two days in Nigeria and Togo and as long as 25 and 27 days in Liberia and Sierra Leone, respectively (table 1). The most common type of COVID-19 vaccines that was initially delivered through the COVAX Facility to all West African countries was the two-dose Covishield vaccine (Oxford Astrazeneca), however, Sinopharm and Sinovac vaccines were also received (figure 1B).

Overall, after three months of the deployment of COVID-19 vaccinations across all ECOWAS countries, only $0.27 \%$ of the total population of the region had
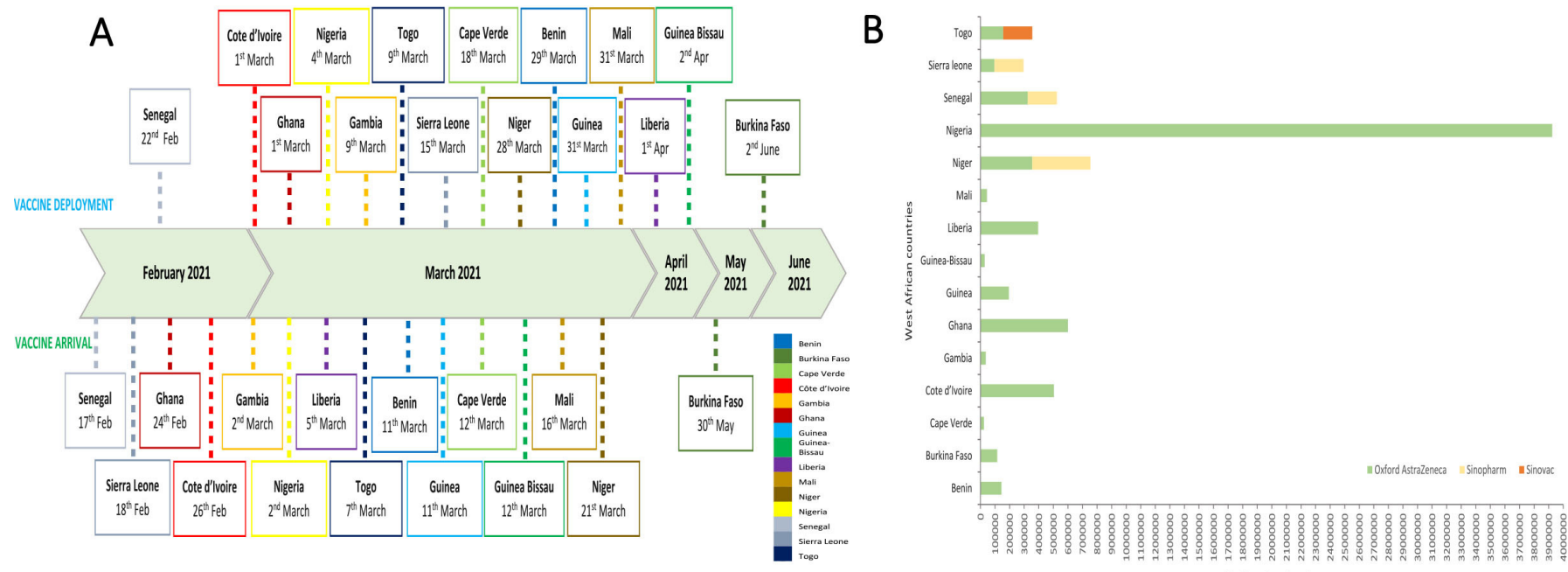

Number of vaccine doses

Figure 1 (A) Timelines of COVID-19 vaccine arrivals and deployments in 15 ECOWAS countries. (B) Types of COVID-19 vaccines received in the 15 ECOWAS countries during the first phase of shipment. ECOWAS, Economic Community of West Africa States. 
Table 1 Country-level background characteristics related to COVID-19 vaccines and COVID-19 epidemiology at the time of vaccine arrival in 15 West African countries

\begin{tabular}{|c|c|c|c|c|c|}
\hline Countries & $\begin{array}{l}\text { Country total } \\
\text { population* }\end{array}$ & $\begin{array}{l}\text { No of COVID-19 } \\
\text { vaccines doses } \\
\text { initially received }\end{array}$ & $\begin{array}{l}\text { Arrival of vaccines to } \\
\text { deployment duration } \\
\text { (days) }\end{array}$ & $\begin{array}{l}\text { COVID-19 cases per } \\
100000 \text { population as of } \\
\text { vaccine arrival }\end{array}$ & $\begin{array}{l}\text { COVID deaths per } 100 \\
000 \text { population as of } \\
\text { vaccine arrival }\end{array}$ \\
\hline Benin & 12451000 & 144000 & 18 & 55 & 0.47 \\
\hline Burkina Faso & 21497000 & 115200 & 3 & 66 & 0.33 \\
\hline Cape Verde & 556000 & 24000 & 6 & 2907 & 528.6 \\
\hline Côte d'Ivoire & 27054000 & 504000 & 3 & 126 & 0.49 \\
\hline Gambia & 2487000 & 36000 & 7 & 201 & 8.55 \\
\hline Ghana & 31732000 & 600000 & 5 & 267 & 0.88 \\
\hline Guinea & 13497000 & 194400 & 20 & 164 & 1.28 \\
\hline Guinea-Bissau & 2015000 & 28800 & 21 & 192 & 9.97 \\
\hline Liberia & 5180000 & 396000 & 27 & 45 & 0.96 \\
\hline Mali & 20856000 & 44286 & 15 & 54 & 0.29 \\
\hline Niger & 25131000 & 400000 & 7 & 23 & 0.11 \\
\hline Nigeria & 211401000 & 3924000 & 2 & 66 & 0.03 \\
\hline Senegal & 17196000 & 200000 & 5 & 195 & 1.20 \\
\hline Sierra Leone & 8141000 & 200000 & 25 & 49 & 0.63 \\
\hline Togo & 8478000 & 156000 & 2 & 94 & 1.16 \\
\hline
\end{tabular}

This table shows the total population of each of ECOWAS countries according to the UN Population Prospects 2020, number of COVID-19 vaccines doses initially received in the first shipments, duration of arrival of vaccines in the country to vaccine deployment, COVID-19 cases per 100000 population and COVID deaths per 100000 population as of vaccine arrival.

*Based on the UN Population Prospects 2020.

ECOWAS, Economic Community of West Africa States.

been fully vaccinated (figure 2), with Guinea, Ghana, Togo and Cape Verde having the highest proportions of their populations being fully vaccinated at $1.3 \%, 1.2 \%$, $0.9 \%$ and $0.5 \%$ of the total population, respectively. Côte d'Ivoire, Burkina Faso and Liberia had the lowest proportions $(0.01 \%, 0.02 \%$ and $0.05 \%)$ of their population fully vaccinated after three months of the vaccine deployment (figure 2B).

If the ECOWAS countries follow the speed of vaccination and/or the trajectory of the population fully vaccinated at
$0.27 \%$ after three months, the sub-region will be well below $1.6 \%$ of the total population to receive full vaccination after 18 months of commencement of the vaccinations (figure 3). To achieve a COVID- 19 vaccination coverage of at least $60 \%$ of the total population in West Africa at 9,12 and 18 months after deployment of the vaccines, the speed of vaccination must be increased to 10,7 and 4 times of the current trajectory, respectively. A similar increase in rate is also needed at the country levels to ensure $60 \%$ of the total population is fully vaccinated at 9,12 and 18 months after vaccine deployment (figure 4).
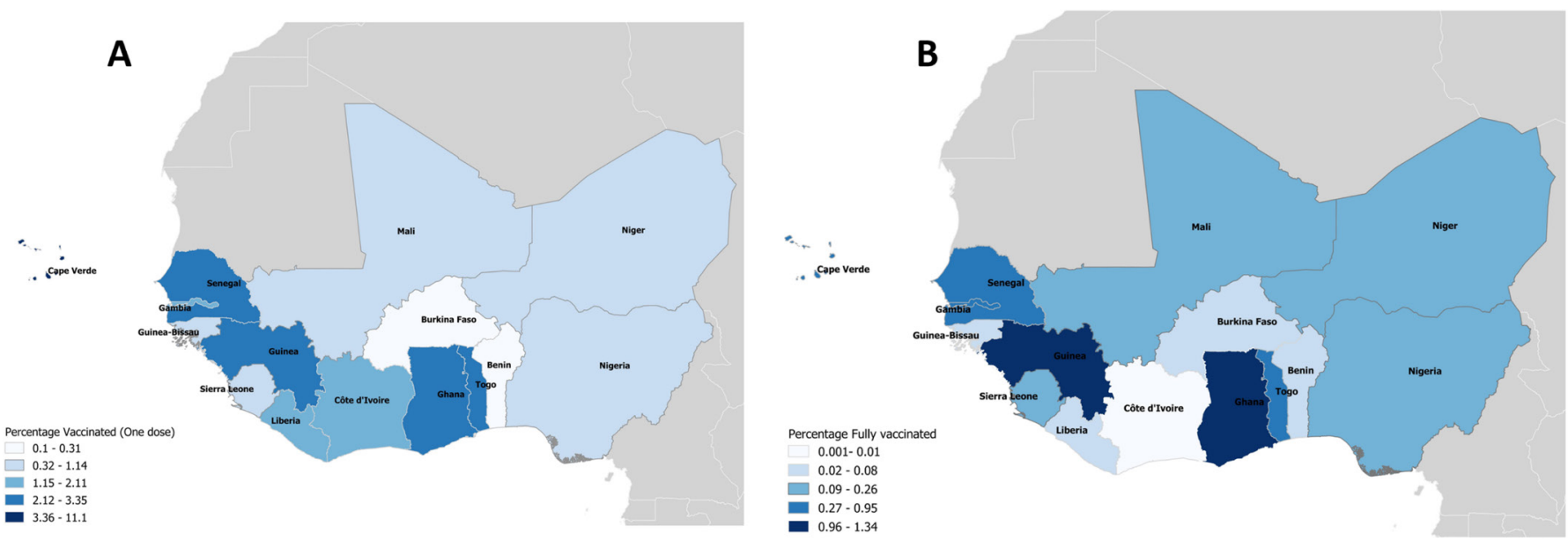

Figure 2 Cartographic representations of the COVID-19 vaccination coverage in 15 ECOWAS countries showing the proportion of people (A) who received at least one dose and (B) who received two (full) doses of the vaccine, 3 months after deployment. ECOWAS, Economic Community of West Africa States. 


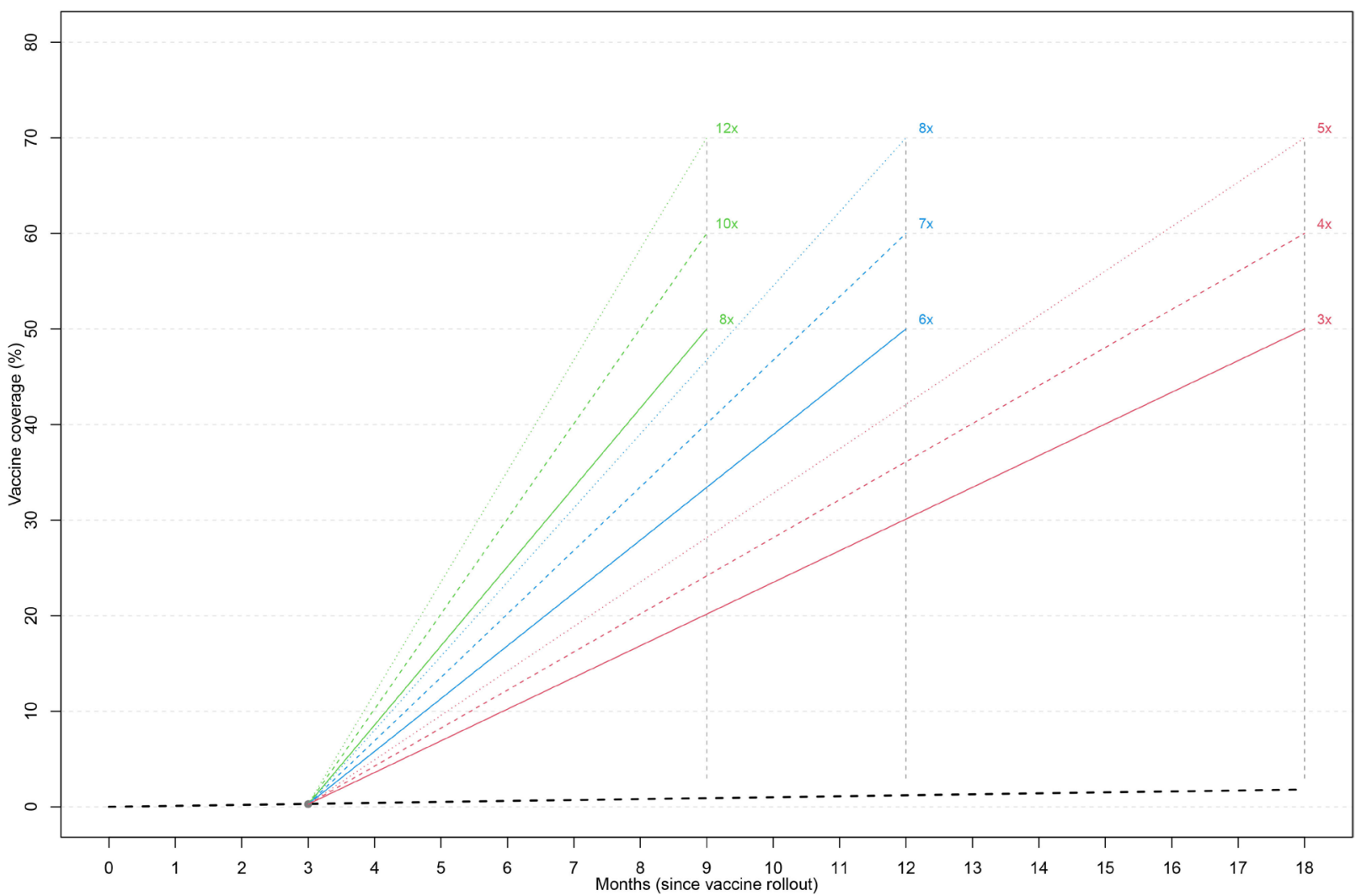

Figure 3 The projected trajectory to achieve full vaccination in 50\%, 60\% and $70 \%$ of the population after 9,12 and 18 months of vaccine deployment in west Africa.

\section{INTERPRETATIONS OF THE FINDINGS}

Shipment of COVID-19 vaccines to West African countries started as early as February 2021, barely two months after the vaccine roll-out in HICs. The relatively early shipment of COVID-19 vaccines to West Africa inspired the belief that COVAX initiative might achieve its intended objectives. However, the novel initiatives aimed at achieving equitable access to COVID-19 vaccines by LMICs have been hampered by vaccine nationalism and hoarding by wealthy countries, export restrictions and difficulty in scaling-up production, ${ }^{20}$ which affected the Johnson \& Johnson and AstraZeneca vaccines. Other challenges included delays in obtaining Emergency Use Authorisation approvals from the WHO by candidate vaccines such as Novavax, SII-Novavax, and Clover, lack of funds and readiness at the country level. ${ }^{21}$ Also, the Serum Institute of India, a key supplier for the COVAX initiative, halted vaccine exports due to an overwhelming outbreak of COVID-19 in India, requiring the company to be able to meet the enormous local needs. ${ }^{20}$ This national action severely limited the production and delivery of AstraZeneca vaccines for international use, with significant negative impact especially felt in West African countries with limited alternative sources of the vaccine supply.

Overall, COVID-19 vaccination rates across West African countries remain very low after at least three months of deployment of the vaccines, as only $0.27 \%$ of the population have been fully vaccinated, compared with other African sub-regions such as Southern and North
Africa where higher proportions of the populations were vaccinated during the same period, despite receiving a proportional supply of the COVID-19 vaccine doses. ${ }^{6} 1722$ It is inappropriate to generalise the whole of Africa as having a young population, with a huge proportion in the informal sector with high unemployment rates, political instability, insecurity and limited trust in government as factors impacting negatively on COVID-19 vaccine uptake. ${ }^{23}$ Nevertheless, it is important to highlight the contextual peculiarities accounting for the deficient uptake in West Africa compared with other sub-regions in Africa, given its grave implication on the COVID-19 epidemiology, vis-a-vis emergence of COVID-19 variants, increasing morbidity and mortality, social and economic losses for West African countries and similar environments with sub-optimal immunisation coverage.

The need to pre-position massive vaccine storage and delivery capacity (fast and slow cold chain equipment) powered by clean energy across all levels of vaccine supply management systems in most West African countries may explain the time lag between vaccine arrival and delivery to end-users. Also, the limited number of delivery points due to a shortage of funding for staffing and health infrastructures has likely contributed to the sub-optimal uptake of COVID-19 vaccines. ${ }^{9}{ }^{10}$ One approach that could address the limited number of points of vaccination service delivery and improve uptake is integration of COVID-19 vaccination into the routine immunisation schedule. ${ }^{24}$ Although an inadequate 


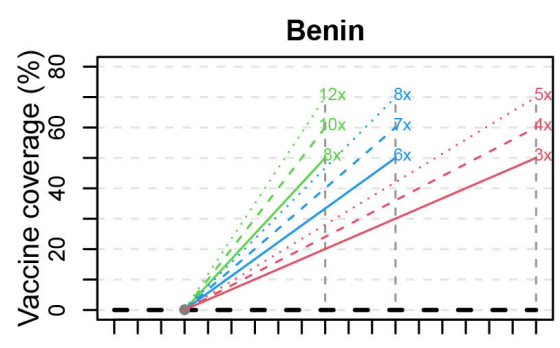

$\begin{array}{llllllllll}0 & 2 & 4 & 6 & 8 & 10 & 12 & 14 & 16 & 18\end{array}$

Côte d'Ivoire

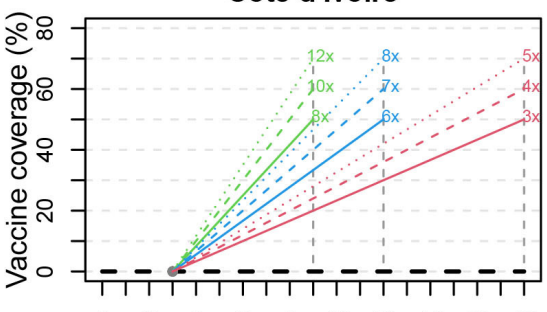

$\begin{array}{llllllllll}0 & 2 & 4 & 6 & 8 & 10 & 12 & 14 & 16 & 18\end{array}$
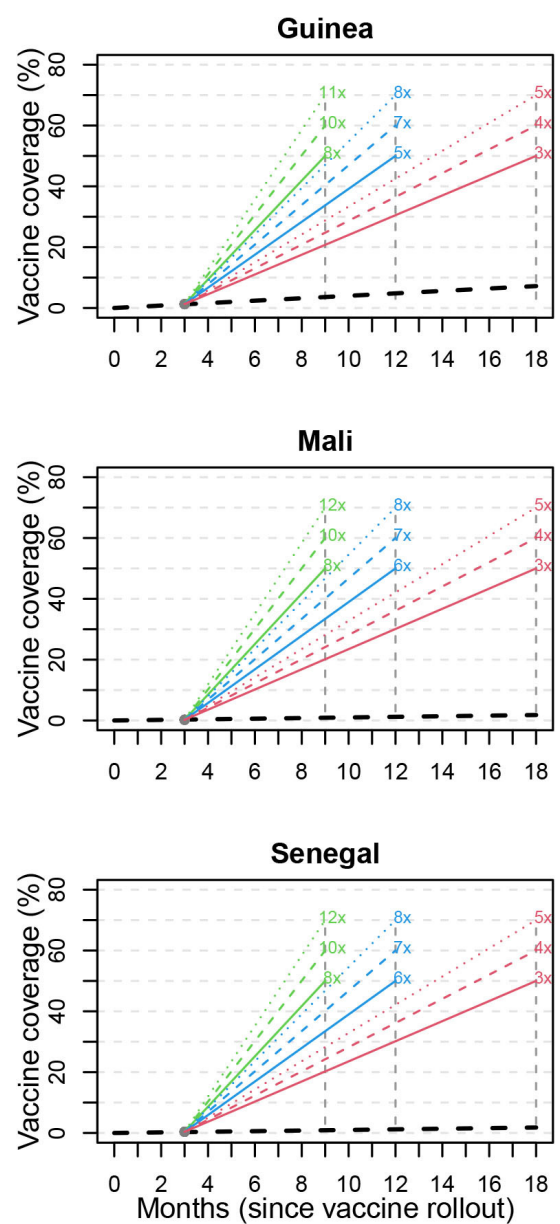

Burkina Faso

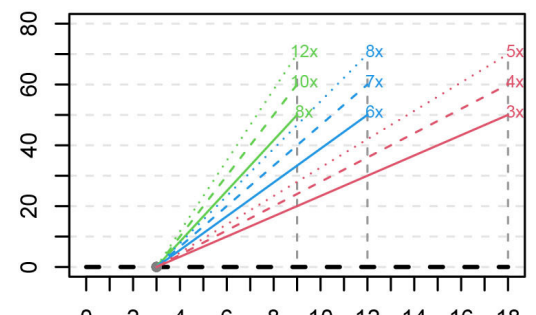

$\begin{array}{llllllllll}0 & 2 & 4 & 6 & 8 & 10 & 12 & 14 & 16 & 18\end{array}$

Gambia

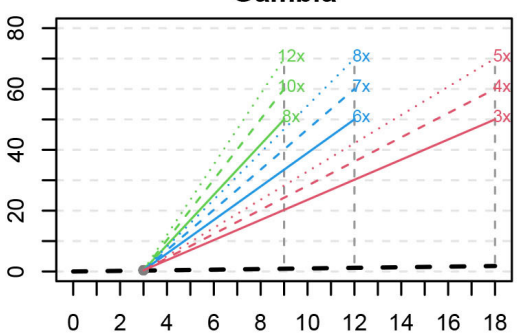

Guinea-Bissau
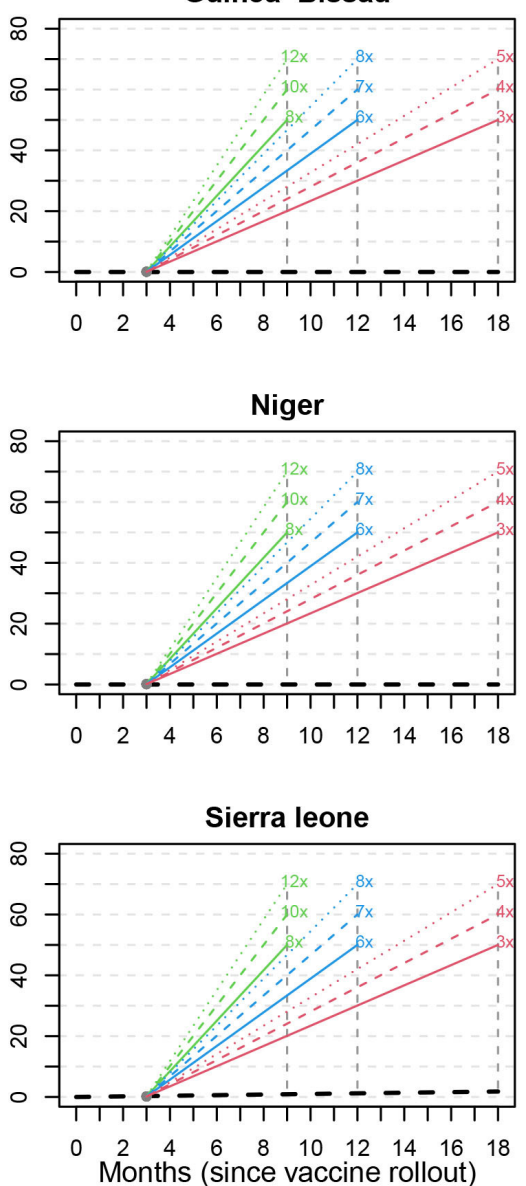

Cape Verde

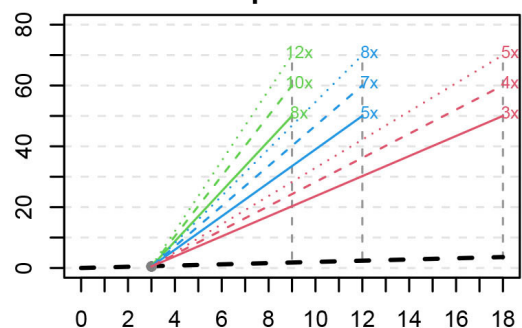

Ghana

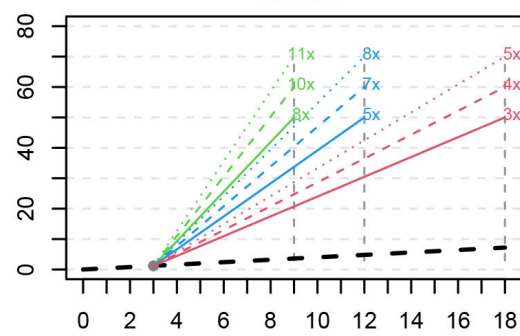

Liberia

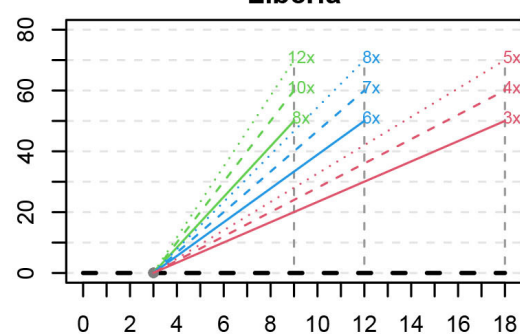

Nigeria
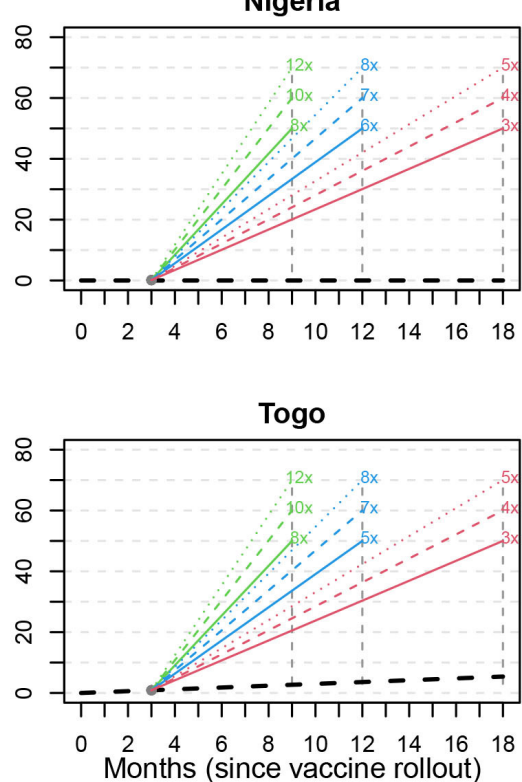

Figure 4 The projected trajectory to achieve full vaccination in 50\%, 60\%, and $70 \%$ of the population after 9 , 12 and 18 months of vaccine deployment in each of the 15 ECOWAS member states. ECOWAS, Economic Community of West Africa States.

supply of vaccines could challenge this approach, concurrent delivery of COVID-19 vaccines with Expanded Programme on Immunisation (EPI) vaccines in health facilities providing routine immunisations in the subregion will obviate additional costs such as human resources and logistics. ${ }^{25}$ For example, the COVID-19 vaccination programme is being challenged in Nigeria by limited logistics including insufficient data bundle for electronic data management and inadequate funding for vaccination teams' mobility. ${ }^{26}$ The Ivorian government 
deployed mobile clinics and medically equipped buses to the busiest areas to raise awareness, educate and deliver COVID-19 vaccines, which improved the uptake of the vaccines in the urban settlements. ${ }^{27}$ However, this was too little to significantly change the national vaccination rate amidst vaccine shortage. The downside of this approach is the huge financial and logistical requirements for its implementation.

Our analysis suggests that the ECOWAS region can achieve the COVID-19 vaccination coverage of at least $60 \%$ of the total population after 9,12 and 18 months of the vaccine deployment by increasing the current vaccination rates by 10, 7 and 4 times, respectively. This calls for prioritisation of access to vaccines by national governments of ECOWAS countries through adequate emergency funding provisions for more bilateral agreements with vaccine manufacturers in order to complement the COVAX initiatives and the AVATT of the African Union. African countries with strong financial powers to preorder COVID-19 vaccines fared better in terms of vaccination rates than West African countries that relied heavily or solely on the COVAX and the AVATT. The WHO-led COVAX initiative and African Union Task Team hope to achieve the delivery of 720 million doses of COVID-19 vaccines to attain a target coverage of $60 \%$ by June $2022 .{ }^{15}$ This commitment was premised on initial epidemiological risk assessments, which did not take into account the changes in the epidemiology of the infection, for example, increasing infection in children being reported and the viral behaviour. This realisation implies a need to vaccinate other segments of the population, thus providing greater population immunisation coverage. To address the challenge of vaccine hesitancy currently encountered in the COVID-19 vaccination programmes in the West African sub-region, ${ }^{28}$ national governments and partners need to adopt culturally acceptable, community-led strategies to implement effective messaging that highlights the risks and benefits of vaccination, addresses the myths and misconceptions about COVID-19 vaccinations. ${ }^{29}$ For example, in Côte d'Ivoire, the political leadership enlisted community influencers, religious and community leaders to address vaccine hesitancy. ${ }^{16}$ Adopting this strategy in all ECOWAS countries would improve vaccination uptake and reduce the time lag between the arrival of vaccines and vaccine delivery.

Given that public trust, confidence and acceptance of vaccinations can be enhanced if clinical trials that demonstrate a vaccine's efficacy and safety are undertaken locally, ${ }^{30}$ the calls for the conduct of more clinical trials and local manufacturing of COVID-19 vaccines in the West African sub-region remain strident and critically germane. Beyond the advantage of access to lifesaving vaccines, there are potential secondary benefits of vaccine research and development and local manufacturing capacities such as reduced or no cost of importation, less cold chain requirements and economic benefits to the host country. Establishment of this platform would also be useful for research and development for other vaccines targeted at diseases of public health importance in the region-Ebola, Lassa, cholera, meningococcal meningitis, and recently, Marburg.

Our analysis has a few limitations. The analysis focused on the first 90 days after deployment of COVID-19 vaccines. Following the shipment of the first batches of COVID-19 vaccines by COVAX and subsequent roll-outs in West African countries, there was a huge gap in the shipment of subsequent supplies, and the vaccination rates declined dramatically. The re-commencement of the vaccine shipments in July 2021 has not significantly changed the vaccine performance and uptake across West African countries; hence, our analysis still reflects the prevailing situations of COVID-19 vaccination implementations in West Africa. Also, we adopted simple linear interpolations of the vaccination trajectory. Although, the trajectories may deviate from linearity in some countries, these average trajectories allow much needed simplicity (over complex mathematical models) while providing reasonable estimates for the rate of vaccine coverage required to achieve targeted levels at specified time points.

\section{CONCLUSION}

The COVID-19 vaccination coverage in the 15 ECOWAS member states was very low, three months after the vaccine deployment. The West African governments need to deploy contextually relevant and culturally acceptable strategies for COVID-19 vaccine procurements, distributions and implementations to improve the meagre COVID-19 vaccination rates and achieve reasonable coverage to save lives, sooner rather than later.

\section{Author affiliations}

${ }^{1}$ Department of Disease Control, London School of Hygiene \& Tropical Medicine, London, UK

${ }^{2}$ Department of Infectious Disease Epidemiology, London School of Hygiene \& Tropical Medicine, London, UK

${ }^{3}$ Vaccines and Immunity Theme, Medical Research Council Unit The Gambia at London School of Hygiene \& Tropical Medicine, Fajara, The Gambia

${ }^{4}$ Clinton Health Access Initiative, Yaounde, Cameroon

${ }^{5}$ Institute for Global Health, University of Siena, Siena, Italy

${ }^{6}$ Department of Infection and Travel Medicine, Leeds Teaching Hospitals NHS Trust, Leeds, UK

${ }^{7}$ Department of Internal Medicine, College of Medical Sciences, Faculty of Clinical Sciences, University of Calabar, Calabar, Cross River State, Nigeria

${ }^{8}$ Field Presence, World Health Organization, Binrin Kebbi, Nigeria

${ }^{9}$ Nuffield Centre for International Health and Development, University of Leeds, Leeds, UK

${ }^{10}$ College of Agriculture, Engineering and Environmental Design, Legacy University, Banjul, Gambia

${ }^{11}$ Statistics \& Bioinformatics, Medical Research Council Unit The Gambia at London School of Hygiene \& Tropical Medicine, Fajara, The Gambia

${ }^{12}$ School of Public Health, Faculty of Health, University of Technology Sydney, Liverpool, New South Wales, Australia

${ }^{13}$ College of Public Health, Medical and Veterinary Sciences, James Cook University, Townsville, Queensland, Australia

${ }^{14}$ Department of Estate Management, Takoradi Technical University, Takoradi, Ghana

${ }^{15}$ Resolve to Save Lives, (Vital Strategies), Regus 4th Floor, Tower C, Churchgate Plaza, 473 Constitution Avenue, Central Business District, Abuja, Nigeria 
${ }^{16}$ World Health Organization, Country Office, Abuja, Nigeria

${ }^{17}$ World Health Organization, Geneve, Switzerland

${ }^{18}$ School of International Development and Global Studies, University of Ottawa, Ottawa, Ontario, Canada

${ }^{19}$ The George Institute for Global Health, Imperial College London, London, UK

Twitter Muhammed Olanrewaju Afolabi @AfolabiLanfol, Oghenebrume Wariri @drwariri, Semeeh Akinwale Omoleke @SEMEEH, Bassey Ebenso @B_Ebenso, Edward Kwabena Ameyaw @edward_ameyaw and Terna Nomhwange @Ennynite

Acknowledgements The authors thank Professor Brian Greenwood for reviewing the manuscript and for providing financial support towards publication of this paper. We also appreciate Dr Sidy Ndiaye of the WHO AFRO Office for supporting the data curation for this study.

Contributors MOA conceptualised and coordinated the study, with inputs from OW. YS, OW, MOA extracted the data. NIM, AA, MO, BOK, EKA and A-AS performed statistical analysis of the datasets. NIM, AA and OW generated the figures. MOA, $\mathrm{OW}, \mathrm{SAO}, \mathrm{BE}, \mathrm{KS}$ and $\mathrm{AO}$ drafted different sections of the manuscript. All authors reviewed and approved the final draft of the manuscript.

Funding The authors have not declared a specific grant for this research from any funding agency in the public, commercial or not-for-profit sectors.

Map disclaimer The inclusion of any map (including the depiction of any boundaries therein), or of any geographic or locational reference, does not imply the expression of any opinion whatsoever on the part of BMJ concerning the legal status of any country, territory, jurisdiction or area or of its authorities. Any such expression remains solely that of the relevant source and is not endorsed by BMJ. Maps are provided without any warranty of any kind, either express or implied.

Competing interests None declared.

Patient consent for publication Not applicable.

Ethics approval This analysis involves data from human participants and was approved by the London School of Hygiene and Tropical Medicine Research Ethics Committee (LSHTM Ethics Ref: 26179).

Provenance and peer review Not commissioned; externally peer reviewed.

Data availability statement All data relevant to the analysis are included in the article or uploaded as supplementary information.

Supplemental material This content has been supplied by the author(s). It has not been vetted by BMJ Publishing Group Limited (BMJ) and may not have been peer-reviewed. Any opinions or recommendations discussed are solely those of the author(s) and are not endorsed by BMJ. BMJ disclaims all liability and responsibility arising from any reliance placed on the content. Where the content includes any translated material, BMJ does not warrant the accuracy and reliability of the translations (including but not limited to local regulations, clinical guidelines, terminology, drug names and drug dosages), and is not responsible for any error and/or omissions arising from translation and adaptation or otherwise.

Open access This is an open access article distributed in accordance with the Creative Commons Attribution Non Commercial (CC BY-NC 4.0) license, which permits others to distribute, remix, adapt, build upon this work non-commercially, and license their derivative works on different terms, provided the original work is properly cited, appropriate credit is given, any changes made indicated, and the use is non-commercial. See: http://creativecommons.org/licenses/by-nc/4.0/.

\section{ORCID iDs}

Muhammed Olanrewaju Afolabi http://orcid.org/0000-0002-9967-6419

Oghenebrume Wariri http://orcid.org/0000-0002-7432-8995

Akaninyene 0tu http://orcid.org/0000-0002-6009-2707

Semeeh Akinwale Omoleke http://orcid.org/0000-0003-0538-9126

Bassey Ebenso http://orcid.org/0000-0003-4147-0968

Bright Opoku Ahinkorah http://orcid.org/0000-0001-7415-895X

Edward Kwabena Ameyaw http://orcid.org/0000-0002-6617-237X

Abdul-Aziz Seidu http://orcid.org/0000-0001-9734-9054

Nuredin Ibrahim Mohammed http://orcid.org/0000-0002-4067-1103

Sanni Yaya http://orcid.org/0000-0002-4876-6043

\section{REFERENCES}

1 Solís Arce JS, Warren SS, Meriggi NF, et al. COVID-19 vaccine acceptance and hesitancy in low- and middle-income countries. Nat Med 2021;27:1385-94.
2 Global dashboard for vaccine equity. Available: https://data.undp. org/vaccine-equity/ [Accessed 20 Sep 2021].

3 Vaccine inequity causes 'dangerous divergence' in COVID survival rates - UN agency heads. Available: https://www.globalissues.org/ news/2021/08/27/28604 [Accessed 2 Sep 2021].

4 WHO director-general's opening remarks at 148th session of the executive board. Available: https://www.who.int/director-general/ speeches/detail/who-director-general-s-opening-remarks-at-148thsession-of-the-executive-board [Accessed 1 Sep 2021].

5 Nine in 10 African countries set to miss urgent COVID-19 vaccination goal. Available: https://www.afro.who.int/news/nine-10-africancountries-set-miss-urgent-covid-19-vaccination-goal [Accessed 1 Sep 2021].

6 WHO Africa COVID-19 dashboard. Available: https://rebrand.ly/ WHOAFRO-covid-19-vaccine-Update [Accessed 2 Sep 2021].

7 Stigma related to COVID-19 may thwart prevention efforts. Available: https://ccp.jhu.edu/2021/02/08/covid-stigma-prevention-ivorycoast/ [Accessed 20 Sep 2021]

8 Acheampong T, Akorsikumah EA, Osae-Kwapong J, et al. Examining vaccine Hesitancy in sub-Saharan Africa: a survey of the knowledge and attitudes among adults to receive COVID-19 vaccines in Ghana. Vaccines 2021;9:814.

9 Head M, Brackstone K, Akinocho H. Examen des déterminants de I'hesitation a la vaccination au Togo contre la COVID-19 figshare $2021 \mathrm{https} / / / \mathrm{doiorg} / 106084 / \mathrm{m} 9$ figshare14806374v1

10 Brackstone K, Boateng LA, Atengble K. Examining drivers of COVID-19 vaccine hesitancy in Ghana. figshare 2021

11 Otu A, Osifo-Dawodu E, Atuhebwe P, et al. Beyond vaccine hesitancy: time for Africa to expand vaccine manufacturing capacity amidst growing COVID-19 vaccine nationalism. Lancet Microbe 2021;2:e347-8.

12 Communiqué of the African Union (AU) Bureau of Heads of State and Government Meeting. Available: https://au.int/en/ pressreleases/20200403/communique-african-union-au-bureauheads-state-and-government-teleconference [Accessed $28 \mathrm{Jul}$ 2021].

13 Economic Community of West African States. Member states. Available: https://www.ecowas.int/member-states/ [Accessed 28 Mar 2020].

14 UN Department of Economic and Social Affairs Population Dynamics. World population prospects 2019, 2019. Available: https://population.un.org/wpp/Download/Standard/Population [Accessed 1 Sep 2021].

15 COVAX facility_GAVI. Available: https://www.gavi.org/covax-facility [Accessed 1 Sep 2021].

16 The world bank and the African union's covid-19 Africa vaccine acquisition task team (AVATT) agree to work together to deploy vaccines for 400 million Africans. Available: https://www.uneca.org/ stories/the-world-bank-and-the-african-union $\% E 2 \% 80 \% 99$ s-covid19-africa-vaccine-acquisition-task-team-\%28avatt\%29 [Accessed 2 Sep 2021].

17 Our world in data. Available: https://ourworldindata.org/coronavirus [Accessed 1 Sep 2021].

18 Syntia Munung N, Ujewe SJ, Afolabi MO. Priorities for global access to life-saving interventions during public health emergencies: crisis nationalism, solidarity or charity? Glob Public Health 2021:1-10.

19 R Core Team. R: a language and environment for statistical computing. R foundation for statistical computing, Vienna, Austria, 2021. Available: https://www.R-project.org/ [Accessed 20 Sep 2021].

20 How rich countries undermine Covax's vaccine equality initiative. Available: https://www.telegraphindia.com/world/how-richcountries-undermine-covaxs-vaccine-equality-initiative/cid/1831215 [Accessed 20 Sep 2021].

21 Wouters OJ, Shadlen KC, Salcher-Konrad M, et al. Challenges in ensuring global access to COVID-19 vaccines: production, affordability, allocation, and deployment. Lancet 2021;397:1023-34.

22 Africa CDC vaccine dashboard. Available: https://africacdc.org/ covid-19-vaccination/ [Accessed 20 Sep 2021].

23 Wirsiy FS, Nkfusai CN, Ako-Arrey DE, et al. Acceptability of COVID-19 vaccine in Africa. Int J MCH AIDS 2021:10:134-8.

24 Afolabi AA, Ilesanmi OS. Dealing with vaccine hesitancy in Africa: the prospective COVID-19 vaccine context. Pan Afr Med J 2021;38

25 Nachega JB, Sam-Agudu NA, Masekela R, et al. Addressing challenges to rolling out COVID-19 vaccines in African countries. Lancet Glob Health 2021;9:e746-8.

26 Nigeria: iMMAP/DFS COVID-19 situation analysis. Available: https:// reliefweb.int/report/nigeria/nigeria-immapdfs-covid-19-situationanalysis-june-2021 [Accessed 20 Sep 2021].

27 COVID-19 vaccines: from rejection to shortage, how Côte d'Ivoire became a model for managing vaccine hesitancy. Available: https://www.worldbank.org/en/news/feature/2021/09/07/covid-19- 
vaccines-from-rejection-to-shortage-how-c-te-d-ivoire-became-amodel-for-managing-vaccine-hesitancy [Accessed 20 Sep 2021].

28 AD432: Who wants COVID-19 vaccination? In 5 West African countries, hesitancy is high, trust low. Available: https://

afrobarometer.org/publications/ad432-who-wants-covid-19vaccination-5-west-african-countries-hesitancy-high-trust-low? page $=18$ [Accessed 20 Sep 2021]
29 Omoleke SA, Bayugo YV, Oyene U, et al. WHO Community

Engagement Package: A Reinforcement of an Inclusive Approach to Public Health. Int J Epidemiol Health Sci 2021;2.

30 Salami K, Imbault N, Erlebach A, et al. A systematic scorecardbased approach to site assessment in preparation for Lassa fever vaccine clinical trials in affected countries. Pilot Feasibility Stud 2020;6:24. 